\title{
Does Plan B work? Home range estimations from stored on board and transmitted data sets produced by GPS-telemetry in the Colombian Amazon
}

\author{
Jaime A. Cabrera, Eduardo Molina, Tania González \& Dolors Armenteras \\ Grupo de Ecología de Paisajes y Modelación de Ecosistemas (ECOLMOD), Departamento de Biología, Edificio 421, \\ Oficina 223, Universidad Nacional de Colombia, Bogotá, Colombia; jaacabrera@unal.edu.co, \\ emolinago@unal.edu.co,tmgonzalezd@unal.edu.co,darmenterasp@unal.edu.co
}

Received 04-XII-2015. C Corrected 29-VI-2016. $\quad$ Accepted 28-VII-2016.

\begin{abstract}
Telemetry based on Global Positioning Systems (GPS) makes possible to gather large quantities of information in a very fine scale and work with species that were impossible to study in the past. When working with GPS telemetry, the option of storing data on board could be more desirable than the sole satellite transmitted data, due to the increase in the amount of locations available for analysis. Nonetheless, the uncertainty in the retrieving of the collar unit makes satellite-transmitted technologies something to take into account. Therefore, differences between store-on-board (SoB) and satellite-transmitted (IT) data sets need to be considered. Differences between SoB and IT data collected from two lowland tapirs (Tapirus terrestris), were explored by means of the calculation of home range areas by three different methods: the Minimum Convex Polygon (MCP), the Fixed Kernel Density Estimator (KDE) and the Brownian Bridges (BB). Results showed that SoB and IT data sets for the same individual were similar, with fix ranging from $63 \%$ to $85 \%$ respectively, and $16 \mathrm{~m}$ to 17 $\mathrm{m}$ horizontal errors. Depending on the total number of locations available for each individual, the home ranges estimated showed differences between $2.7 \%$ and $79.3 \%$, for the $50 \%$ probability contour and between $9.9 \%$ and $61.8 \%$ for the $95 \%$ probability contour. These differences imply variations in the spatial coincidence of the estimated home ranges. We concluded that the use of IT data is not a good option for the estimation of home range areas if the collar settings have not been designed specifically for this use. Nonetheless, geographical representations of the IT based estimators could be of great help to identify areas of use, besides its assistance to locate the collar for its retrieval at the end of the field season and as a proximate backup when collars disappear. Rev. Biol. Trop. 64 (4): 1441-1450. Epub 2016 December 01.
\end{abstract}

Key words: brownian bridges, Colombian Amazon, gps telemetry, home range, kernel density estimator, minimum convex polygon, Tapirus terrestris.

The analysis of animal locations, allow the estimation of its home range considered as "the area traversed by the individual in its normal activities" (Burt, 1943). This knowledge provides information to understand how animals interact with their environment and how they use the available resources in heterogeneous landscapes (Cagnacci, Boitani, Powell, \& Boyce, 2010). This kind of information has become very relevant, because it could be the starting point to understand the underlying mechanisms that control biodiversity spatial patterns.

Since 1960s, very high frequency (VHF) telemetry enabled the monitoring of animal locations in a way it was impossible with the old traditional tracking methodologies, which required the permanence of researchers in the field for long periods of time. VHF technology made possible to give a temporal dimension to habitat use data, by means of the approximation to the animal's home ranges over a particular 
time period and by maximizing the quantity of data gathered (Kochanny, Delgiudice, \& Fieberg, 2009; Cagnacci et al., 2010).

After the late 1990s, the development of telemetry based on GPS and the possibility to get data in near-real time scale through satellite networks as Argos or Iridium, has changed the way telemetry can be done (Tomkiewicz, Fuller, Kie, \& Bates, 2010). Now, it is possible to gather large quantities of information in a very fine scale and work with species that were impossible to study in the past, because the excessive field logistics required to access the vast tracts of wilderness where these species still exist (Cagnacci et al., 2010). The Amazon basin, one of the most unexplored areas in the world, is one of those places where GPS telemetry is helpful and provides very much needed information about the ecological characteristics and presence of particular species (Tobler, Carrillo-Percastegui, \& Powell, 2009).

However, GPS technology implies technical and economic challenges. In the economical aspect, it presents the serious drawback of equipment cost, which result in the reduction of the number of individual equipped with collars. In the technical aspect, it has been necessary to develop procedures that deal with large data sets with high spatial autocorrelation and different levels of quality and spatial distribution complexity (Seaman, Millspaugh, Kernohan, Brundige, Raedeke, \& Gitzen, 1999; Kie et al, 2010; Frair et al, 2010; Walter, Fischer, BaruchMordo, \& Vercauteren, 2011). Alongside the above mentioned issues, it is important to consider the contextual biological information that is missed, do to the absence of the researchers in field, and the inconsistency in the analysis of very high resolution animal location data in terms of the almost always coarse thematic cartography (Hebblewhite \& Haydon, 2010).

Usually "more data is better" in order to draw robust conclusions. Therefore, in a project with a major component of GPS-telemetry, storing information in a non-volatile memory will be more desirable than rely in satellite transmitted data which reduce the amount of locations for analysis (Tomkiewicz et al.,
2010). However, the high proportion of collars that fail and/or get lost in the field because the always challenging field conditions present in some environments like the tropics (Tobler, 2009; Castellanos, 2013), make satellite transmitted data a very desirable characteristic. This way, no matter what happen with the collar, at the end of a field season some data will be available. Until now, most researchers have focused their analyses of GPS telemetry to determine biases related to the animal's or environment characteristics (Jung \& Kuba 2015; Mattisson et al 2010). However the potential bias due to the technique itself, as the differences between store-on-board ( $\mathrm{SoB}$ ) and satellite-transmitted (IT) data from the same individual have not been considered.

This reseach explored these potential differences and their implications in the biological conclusions generated, using two extreme examples: a collar that remained working for a long time period (8 months) and a second one that failed after 15 days in the field, due to the very harsh Amazon conditions. The comparisons were made in terms of their fix rate, horizontal error and the resulting home ranges estimations. Home ranges were calculated by three different methodologies traditionally used in telemetry research and evaluated by means of its geometry and spatial coincidence.

\section{MATERIALS AND METHODS}

The study was carried out from July 2014 to January 2015 at the Nonuya de Villazul indigenous Reserve $\left(2650 \mathrm{~km}^{2}\right)$ at the Middle Caquetá river basin (Colombia). This basin is located between the town of Araracuara $\left(0^{\circ} 37^{\prime}\right.$ $\left.\mathrm{S}-72^{\circ} 23^{\prime} \mathrm{W}\right)$ and the mouth of the Cahuinarí River $\left(1^{\circ} 24^{\prime}-70^{\circ} 43^{\prime} \mathrm{W}\right)$. The area comprehends approximately $10000 \mathrm{~km}^{2}$, in which the Caquetá River flows from the Andes in Colombia towards Brazil, representing the largest continuous patch of primary forest in the Colombian Amazon. The reserve contains a dense terra firme forest matrix, with transitional vegetation associated $t$ river islands, terra firme grasslands with shrubs, palm aggregations associated to 
the Caquetá river floodplain, and some high dense flooded forest (Murcia, Huertas, Rodríguez, \& Castellanos, 2010).

In 2014 a Telonics ${ }^{\circledR}$ telemetry collar (TGW-4570-3 GPS/Gen4 GPS-Iridium collar system) were attached to a young male $(>1$ year old) and an adult female lowland tapirs (Tapirus terrestris), in order to monitor their movements. Lowland tapirs are the largest terrestrial mammals in the neotropics, with large area requirements and an important role in the ecological dynamics of the forest (Fragoso, 2003; Keuroghlian \& Eaton, 2009) being also an important source of protein for local populations (Bodmer et al., 2008). The species is under the VU (Vulnerable) IUCN global category (IUCN, 2015) and is part of the II CITES Appendix (UNEP-WCMC, 2012).

The deployed collars combined a GPS receiver, a non-volatile data-log memory and a VHF beacon system. Additionally the collar was supplied with a transfer component that allowed the transmission of data via Iridium satellite network (Telonics, 2013). The collar was programmed to work 24 hour per day, taking a GPS location every hour between 06:00 - 18:00 and one every half hour during the rest of the day. The difference in the acquisition rate was modeled taking into account tapir's nocturnal behavior, aiming to reduce battery consumption. These collars also have an autorelease mechanism that was programed to activate a drop-off mechanism and a VHF beacon that helps to its location after its release.

The scheduled transmission protocol was to gather GPS locations until 340 bytes of information were completed, moment at which the collar tries to transmit it through the Iridium satellite network, for up to 20 seconds (IT data set). Sometimes, due to weather, canopy cover, topography, among others, the transmission was not possible, in which case, the information was stored on board and a new batch of 340 bytes started to be gathered. Transmitted and not transmitted information was stored in the GPS memory (SoB data set), to be available when the collar was recovered. The incomplete success rate of the transmission through the
Iridium network determined the differences between IT and SoB data sets

The IT data set included: acquisition time, acquisition start time, Iridium CEP radius, Iridium latitude, Iridium longitude, GPS fix time, GPS fix attempt, GPS latitude, GPS longitude, GPS horizontal error, activity count, receive time, repetition count, GPS satellite count, mortality and transmission error. The SoB data set included all of the above variables, plus GPS fix attempt (3D and 2D), GPS speed, GPS heading, GPS horizontal dilution and GPS satellite bit map.

For each individual, both data sets were characterized in terms of the horizontal error, which represents the precision of the obtained locations and their fix rate, which is the number of successful attempts of obtaining the location coordinates over the total number of attempts. A location attempt was considered successful when the device was able to get the coordinates of the animal location using 3 (2D) or more satellites (3D).

The SoB data was screened, eliminating the $2 \mathrm{D}$ points $\left(\mathrm{n}_{\text {male }}=38 ; \mathrm{n}_{\text {female }}=3\right)$, in order to exclude the locations with largest horizontal error without affecting significantly the size and quality of the IT and SoB data sets (Lewis, Rachlow, Garton, \& Vierling 2007). In order to check if the quality of the data differs between data sets for the same individual, after screening IT and SoB horizontal errors were compared by means of a Student $t$ test. Because our aim is not a comparison of the several available home range calculation methods, we show the most commonly used (Minimum Convex Polygon, Kernel and Brownian Bridges), without making inferences about which method is the best; but evaluating the effects that result from using different data gathering techniques (origin-different data sets) for the same individual. All the calculations were done using the adehabitatHR and $k s$ packages in $R$ software (Calenge, 2006).

For each individual, the resulting home ranges from both data sets were compared in terms of the total calculated area and their spatial coincidence, which was assessed as 
the percentage of Home Range intersection (HR estimate), Volume Intersection statistic (VI) and Bhattacharyya's affinity estimate (BA) (Fieberg \& Kochanny 2005, Kochanny et al., 2009).

\section{RESULTS}

The collar attached to the young male tapir remained active for 197 days. A total of 7859 attempts of localization points were made and stored in the collar's memory (SoB data set), from which $21 \%$ (1 686 attempts) were transmitted through the Iridium network (IT data set). For the adult female, the collar remained attached 15 days, totaling 438 attempts of localization, from which $22 \%$ (100 attempts) were transmitted (Table 1).

The largest SoB data set (male), contained 5237 location attempts that were successfully stored-on-board, reaching a fix rate of $66 \%$. For the female's SoB data set (438 locations) the fix rate was $85 \%$ (Table 1). IT data sets presented a fix rate of $63 \%$ (1071 locations) for the male and $42 \%$ (42 locations) for the female (Table 1). After data screening, there were very few horizontal errors higher than $30 \mathrm{~m}$ in both data sets, and their quality measured as their horizontal error did not differ statistically for each individual ([male: $\mathrm{t}=0.34, \mathrm{p}>0.729$, $\mathrm{df}$ $=6$ 268]; [female: $\mathrm{t}=1.69, \mathrm{p}>0.095, \mathrm{df}=52$ ]); with a mean horizontal error for the male IT of $16.6 \mathrm{~m}(\mathrm{SD}=11.5)$ and $16.7 \mathrm{~m}(\mathrm{SD}=10.8)$ for its $3 \mathrm{D}$ SoB points. In the female data sets the horizontal error was $15.0 \mathrm{~m}(\mathrm{SD}=8.3)$ for IT and $17.4 \mathrm{~m}(\mathrm{SD}=9.62)$ for $3 \mathrm{D} \mathrm{SoB}$ (Table 1).
Except for the consecutiveness dependent method of Brownian Bridges, where the pattern is the opposite, the male's SoB based home range estimations were consistently larger (95\% contour: $9.9 \%$ to $42.8 \%$; $50 \%$ contour: $2.7 \%$ to $22.7 \%$ ), than those resulting from the IT data. SoB based home range estimates for the smaller data set (female) were also larger when compared with IT's (95\% contour: $25 \%$ to $61.8 \%$; $50 \%$ contour: $36.1 \%$ to $79.4 \%$ ), even for the Brownian Bridges method at the $50 \%$ contour (Table 2 ).

For the large data set, the overlap between SoB and IT based home range calculations at $95 \%$ and $50 \%$ contours, were higher than those calculated from the smaller data set (female). For the latter, the home ranges at $95 \%$ presented higher overlaps than those resulting from the calculation at $50 \%$ probability contours (Table 3). Regardless these high overlaps, the shapes and actual geographical locations of the calculated home ranges differ between data sets and consequently could have very different biological interpretations (Fig. 1 and Fig. 2).

\section{DISCUSSION}

The male data set was one of the largest, in terms of number of locations fixes, reported for any mammal using GPS telemetry in tropical forests (Blake, Douglas-Hamilton, \& Karesh, 2003; Boyle, Lourenço, da Silva, \& Smith, 2009; Schuttler, Blake, \& Eggert, 2012; Castellanos, 2013) and particularly for lowland tapirs, which is a very secretive and difficult species to

TABLE 1

Data set characteristics for IT (Iridium Transmitted) and SoB (Store-on-Board) data sets

\begin{tabular}{|c|c|c|c|c|c|c|c|c|c|}
\hline \multirow{2}{*}{$\begin{array}{c}\text { Data } \\
\text { Set }\end{array}$} & \multirow{2}{*}{$\begin{array}{l}\text { Data } \\
\text { Type }\end{array}$} & \multicolumn{4}{|c|}{ Subadult male (Adorno) } & \multicolumn{4}{|c|}{ Adult female (Vitamina) } \\
\hline & & $\mathrm{N}$ & $\%$ & Horizontal error (m) & Fix rate $(\%)$ & $\mathrm{N}$ & $\%$ & Horizontal error (m) & Fix rate $(\%)$ \\
\hline \multirow[t]{4}{*}{ SoB } & $2 \mathrm{D}$ & 38 & 0.5 & 101.73 & & 3 & 0.8 & 19.5 & \\
\hline & $3 \mathrm{D}$ & 5199 & 66.1 & 16.70 & \multirow{2}{*}{66.4} & 376 & 85.2 & 17.44 & \multirow{2}{*}{85.3} \\
\hline & Failed & 2622 & 33.4 & - & & 62 & 14.1 & - & \\
\hline & Total & 7859 & & & & 441 & & & \\
\hline \multirow[t]{3}{*}{ IT } & Succeeded & 1071 & 63.5 & 16.58 & & 58 & 58 & 15.0 & \\
\hline & Failed & 615 & 36.5 & - & \multirow{2}{*}{63.5} & 42 & 42 & - & \multirow{2}{*}{42.0} \\
\hline & Total & 1686 & & & & 100 & & - & \\
\hline
\end{tabular}


TABLE 2

Home range areas estimated for both data set

\begin{tabular}{|c|c|c|c|c|c|}
\hline \multirow[t]{2}{*}{ Data Set } & \multirow[t]{2}{*}{ Method } & \multicolumn{2}{|c|}{$\begin{array}{c}\text { Subadult male } \\
\text { Home Range Area (Ha) }\end{array}$} & \multicolumn{2}{|c|}{$\begin{array}{c}\text { Adult female } \\
\text { Home Range Area (Ha) }\end{array}$} \\
\hline & & $95 \%$ & $50 \%$ & $95 \%$ & $50 \%$ \\
\hline \multirow[t]{3}{*}{ IT } & MCP & 835.4 & 241.0 & 189.5 & 60.5 \\
\hline & $\mathrm{KDE}_{\text {href }}$ & 1242.4 & 217.8 & 685.8 & 136.8 \\
\hline & $\mathrm{BB}$ & 1798.7 & 309.2 & 220.3 & 14.8 \\
\hline \multirow[t]{3}{*}{ SoB } & $\mathrm{MCP}$ & 1460.4 & 311.7 & 495.9 & 293.2 \\
\hline & $\mathrm{KDE}_{\text {href }}$ & 1379.0 & 223.9 & 914.9 & 214.4 \\
\hline & $\mathrm{BB}$ & 834.0 & 81.0 & 337.2 & 9.1 \\
\hline
\end{tabular}

(IT: Iridium Transmitted, SoB: Stored on Board) calculated by different methods (MCP: Minimum Convex Polygon, KDE: Kernel Density Estimator using $\mathrm{h}_{\mathrm{ref}}$; BB: Brownian Bridges) for $95 \%$ and $50 \%$ probability contours.

TABLE 3

Home range overlaps calculated for both data sets

\begin{tabular}{|c|c|c|c|c|c|}
\hline \multirow{3}{*}{$\begin{array}{c}\text { Home Range } \\
\text { Estimator }\end{array}$} & \multirow{3}{*}{ Method } & \multicolumn{4}{|c|}{ Data sets home range overlap at different probability contours } \\
\hline & & \multicolumn{2}{|c|}{ Subadult male } & \multicolumn{2}{|c|}{ Adult female } \\
\hline & & $95 \%$ & $50 \%$ & $95 \%$ & $50 \%$ \\
\hline \multirow[t]{2}{*}{ MCP } & $\mathrm{HR}_{\mathrm{IT} \rightarrow \mathrm{SoB}}$ & 0.99 & 0.92 & 0.99 & 0.94 \\
\hline & $\mathrm{HR}_{\mathrm{SoB} \rightarrow \mathrm{IT}}$ & 0.57 & 0.71 & 0.38 & 0.20 \\
\hline \multirow[t]{4}{*}{$\mathrm{KDE}_{\mathrm{ref}}$} & $\mathrm{HR}_{\mathrm{IT} \rightarrow \mathrm{SoB}}$ & 0.94 & 0.95 & 0.84 & 0.55 \\
\hline & $\mathrm{HR}_{\mathrm{SoB} \rightarrow \mathrm{IT}}$ & 0.84 & 0.92 & 0.64 & 0.34 \\
\hline & VI & 0.76 & 0.41 & 0.52 & 0.18 \\
\hline & BA & 0.89 & 0.46 & 0.85 & 0.85 \\
\hline \multirow[t]{4}{*}{$\mathrm{BB}$} & $\mathrm{HR}_{\mathrm{IT} \rightarrow \mathrm{SoB}}$ & 0.38 & 0.23 & 0.75 & 0.0 \\
\hline & $\mathrm{HR}_{\mathrm{SoB} \rightarrow \mathrm{IT}}$ & 0.93 & 0.65 & 0.30 & 0.0 \\
\hline & VI & 0.54 & 0.19 & 0.25 & 0.0 \\
\hline & BA & 0.71 & 0.24 & 0.46 & 0.0 \\
\hline
\end{tabular}

(IT: Iridium Transmitted, SoB: Stored on Board). HR: Home range intersection estimate, VI: Volume Intersection statistic and BA: Bhattacharyya's affinity estimate for $95 \%$ and $50 \%$ probability contours.

follow in the field (Tobler, 2009). Both IT and SoB data sets provided many more locations than what was normally acquired with the VHF telemetry in the second half of the $20^{\text {th }}$ century and GPS telemetry few years ago, where the usual sample size did not surpass 6000 locations for the same individual with a fix rate lower than $40 \%$ (Blake et al., 2003; Tobler, 2009; Schutler, 2010).

The quality of the data here presented, measured by the horizontal error, also showed the improvement of GPS technology in the last few years; both in terms of precision and performance in challenging environments as tropical rain forest. The reduced amount of $2 \mathrm{D}$ data highlights the benefits of working with GPS telemetry in tropical latitudes where there is high availability of satellites (Tomkiewicz et al., 2010, Frair et al., 2010). Surely, the comparatively flat topography that characterizes Amazon forests also facilitates GPS triangulation, situation that worked in our favor. 


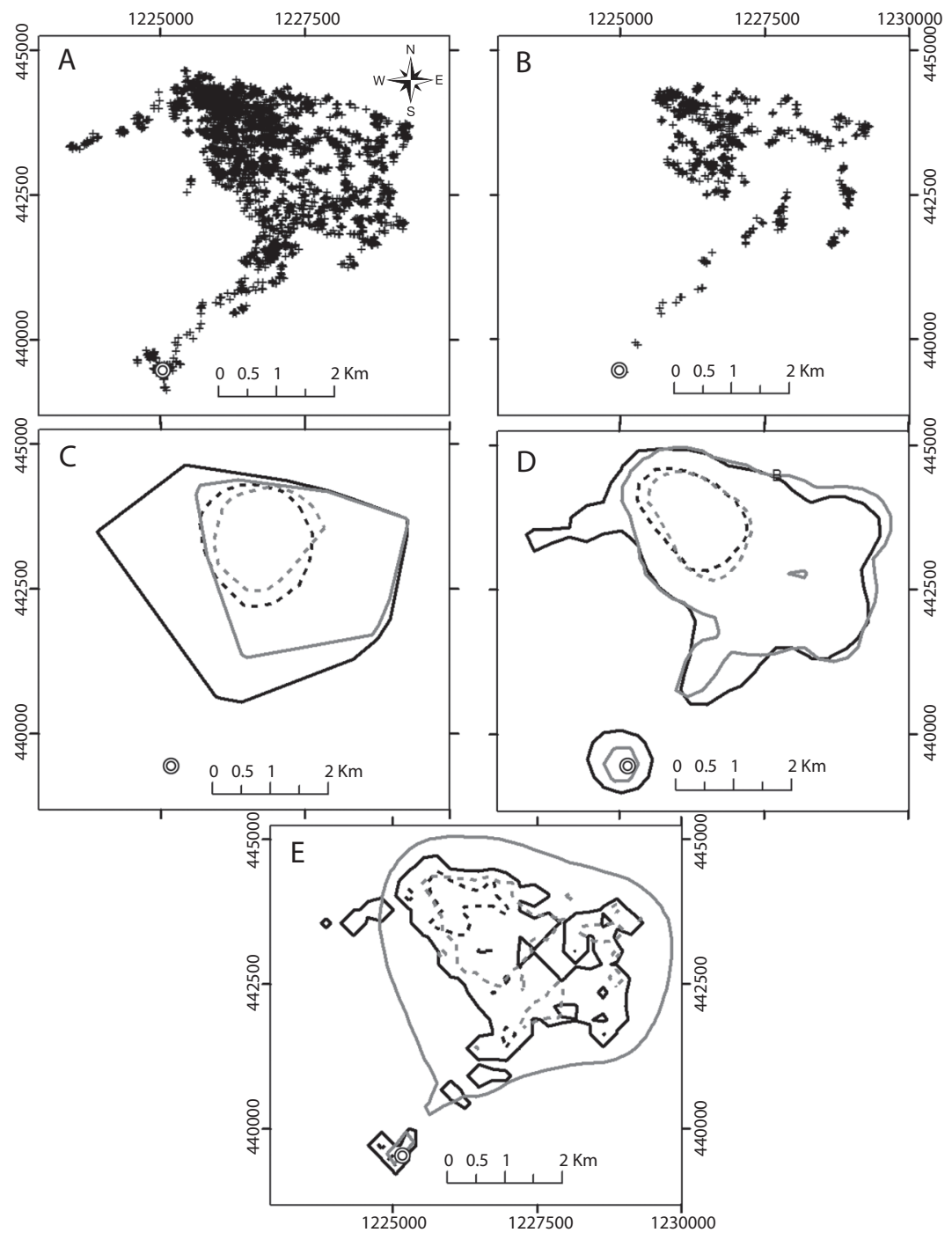

Fig. 1. A) Store-on-Board (SoB) and B) Iridium Transmitted (IT) locations of the sub adult male (Adorno). Home ranges areas estimated by four different methods: C) Minimum Convex Polygon (MCP), D) Kernel Density Estimator with $\mathrm{h}_{\text {ref }}$ smoothing parameter $\left(\right.$ Kernel $_{\text {Ref }}$ ) and E) Brownian Bridges (BB). Graphics shows $95 \%$ (continuous lines) and 50\% probability contours (dotted lines) for SoB (black lines) and IT (gray lines). € Indicates a Salt lick location.

When compared, IT and SoB, data sets were very similar in terms of their mean horizontal error, but not in their extent and spatial coverage. This was expected since the IT data set was necessarily a statistically representative sample from the whole available data ( $\mathrm{SoB}$ ) for each individual. Although the IT and SoB data sets for the same individual were not statistically different in their quality parameters of fix rate and horizontal error, the biological conclusions that can be reached when using each one of them can differ greatly, due to the time span in which they were recorded and the number of locations gathered. When using a large data set gathered over a long time period, which encompasses habitat use variations due to weather and food availability changes, the overlap between IT and SoB generated 

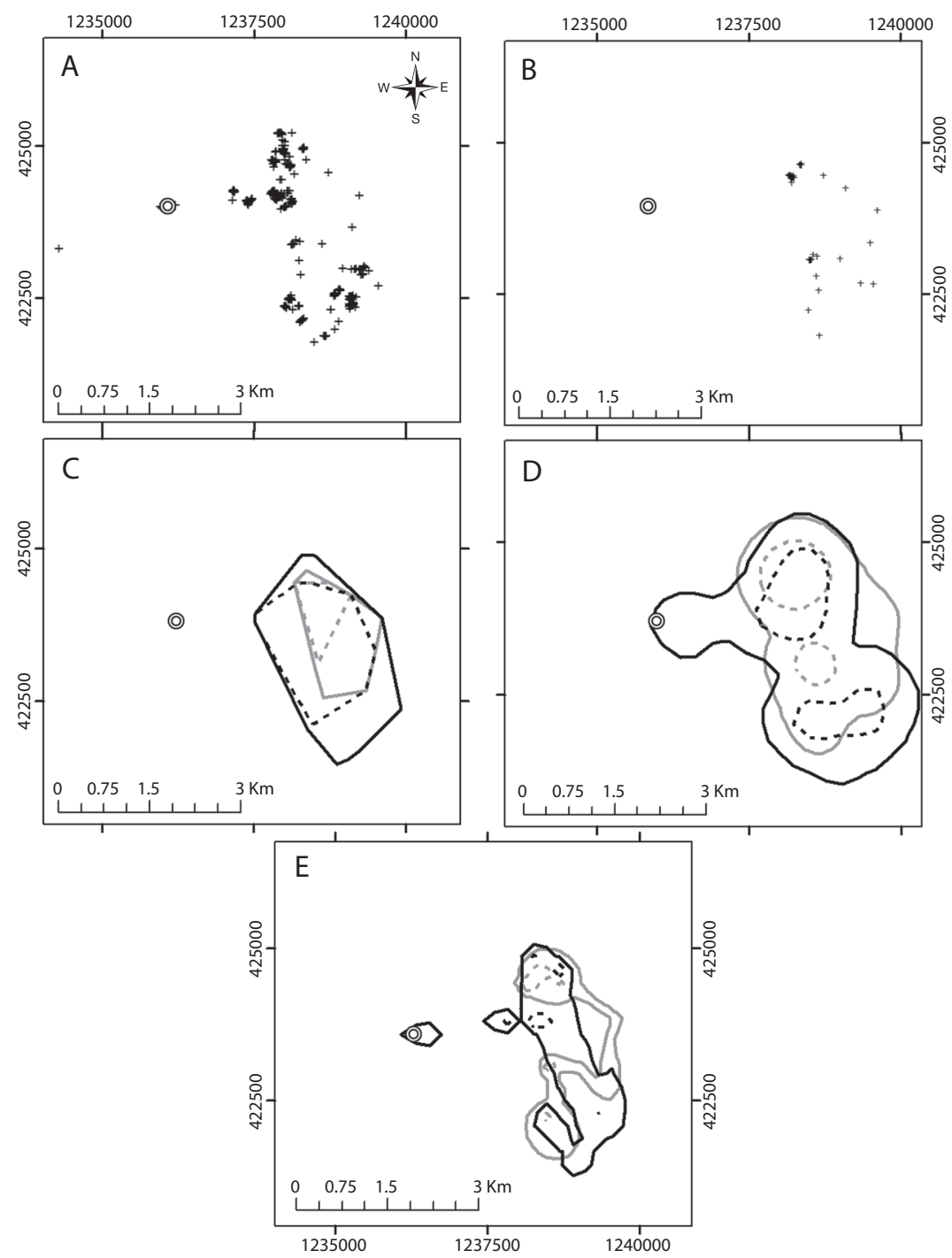

Fig. 2. A) Store-on-Board (SoB) and B) Iridium Transmitted (IT) locations of the adult female (Vitamina). Home ranges areas estimated by four different methods: C) Minimum Convex Polygon (MCP), D) Kernel Density Estimator with $h_{\text {ref }}$ smoothing parameter $\left(\right.$ Kernel $_{\text {Ref }}$ ) and E) Brownian Bridges (BB). Graphics shows $95 \%$ (continuous lines) and $50 \%$ probability contours (dotted lines) for SoB (black lines) and IT (gray lines). € Indicates a Salt lick location.

calculations were considerable and the estimators of the total home range size vary less than when using small data sets, recorded over a small time period.

As expected, our results showed that even using the same data set, conclusions could be very different depending in the estimation methods that are used. Our aim was not to compare home range estimation methods, nonetheless we agree with Walter et al. (2010) when they state that there are no perfect estimators of home range and the choosing will depend mainly on the objectives of the study and on the quantity and quality of the acquired data. That is why we chose to use the most frequently methods to illustrate our point about the differences between data sets.

Although the final home range area calculated is one of the most widely used information, the shape and the actual habitat covered 
by the area estimated can be even more relevant. The biological significance of small areas can be superlative, as has been reported for elements present in the Amazon landscapes like salt licks (Tobler et al., 2009; Cabrera, 2012; Molina, León, \& Armenteras-Pascual, 2014) or palm aggregations (Fragoso \& Huffman 2000; Fragoso, 2003), and this has to be taken into account when analyses are done. For example, in our data the different estimators included a south portion of the area used by the young tapir, but only the Brownian Bridges estimators succeeded to show how it was reached and with that gave a better insight on the habitat use and behavior of a subadult tapir and the importance of small areas in the home range.

When actually trying to answer our question about the validity of conclusions reached from incomplete data sets as those provided via Iridium, our results showed that both data sets could be useful to better understand the ecology of the species and its use of space, but caution should be taken when the main purpose of the study is to determine the extent of the home range areas. Scientists and practitioners should be conscious of this when drawing conclusions. Nowadays GPS telemetry technology is able to reduce horizontal error to levels unthinkable few years ago. However, in the field, after collars are deployed, it is common to find huge difficulties for the retrieval of the collars; due to different causes as poachers disposal of the equipment after illegal activities, impossibility of finding them when they are dropped in the water or simply logistic difficulties to get to the study area, making the Iridium transmission of data, although incomplete, a must in some cases.

\section{ACKNOWLEDGMENTS}

Thank to COLCIENCIAS (grant: 85-2013), Rufford Foundation (grant: 11377B), Universidad Nacional de Colombia and Corporación Tropicis Colombia, which gave us the financial support to develop this project. To Digital Globe Foundation for make available high resolution satellite images. To Paulo Rogerio Mangini who gave us his total support in the field making possible the tapir captures. Finally, we thank to the Nonuya de Villazul indigenous community, who allowed us to work in their territory and gave us their support and insights about tapir biology, especially to Heriberto Andoke, Yimmy Paky and Josefa Díaz, our unconditional guides and friends in field.

\section{RESUMEN}

\begin{abstract}
¿Funciona el plan B? Estimación de rango de hogar a partir de datos almacenados en instrumentos a bordo de animales y los obtenidos a partir de telemetría satelital de GPS en el Amazonas colombiano. La telemetría basada en los sistemas de geopocisionamiento global (GPS) hace posible recopilar gran cantidad de información a escalas muy finas, y trabajar con especies imposibles de estudiar en el pasado. Al trabajar con telemetría de GPS, la opción de guardar información en la memoria interna del instrumento puede ser más deseable que sólo tener acceso a la información enviada vía satélite, debido a la mayor cantidad de localizaciones disponibles para analizar. No obstante, la incertidumbre de recuperar el collar hace que las tecnología de trasmisión vía satélite deba ser tenida en cuenta. Diferencias entre las bases de datos almacenadas en el collar (SoB) y las trasmitidas vía satélite (IT), recolectadas de dos individuos de Tapir de tierras bajas (Tapirus terrestris), son consideradas, en términos de las áreas de los rangos de hogar calculados con cada uno y mediante el uso de tres metodologías diferentes: Mínimo Polígono Convexo (MCP), Estimador de Densidad de Kernel Fijo (KDE) y los Puentes Brownianos (BB). Las bases de datos SoB e IT son similares, con tasas de acierto de localizaciones que oscilan entre $63 \%$ to $85 \%$ y errores horizontales de $16 \mathrm{~m}$ y $17 \mathrm{~m}$ respectivamente. Dependiendo del número total de localizaciones disponibles para cada individuo, los rangos de hogar estimados muestran diferencias entre $2.7 \%$ y 79.3 $\%$, para el contorno del $50 \%$ de probabilidades, y entre 9.9 $\%$ y $61.8 \%$ para el contorno del $95 \%$ de probabilidades. Estas diferencias implican variaciones en la coincidencia espacial de los rangos de hogar estimados. Concluimos que el uso de la información trasmitida vía satélite no es una buena opción para la estimación de rangos de hogar, si la programción de los collares no ha sido diseñada específicamente para tal fin. Sin embargo, las representaciones geográficas de los estimados a partir de las bases de datos IT pueden ser de gran ayuda para la identificación de áreas de uso, además de su utilidad para la localización y recuperación de collares tras su liberación de los individuos monitoreados y como una base de datos de soporte en caso de pérdida del collar.
\end{abstract}


Palabras clave: Puentes brownianos, Amazonía colombiana, telemetría, gps, rango de hogar, estimador de densidad de kernel, mínimo polígono convexo, Tapirus terrestris.

\section{REFERENCES}

Blake, S., Douglas-Hamilton, I., \& Karesh, W. B. (2003). GPS telemetry of forest elephants in Central Africa: results of a preliminary study. African Journal of Ecology, 39, 178-186.

Bodmer, R., Puertas, P., \& Fang, T. G. (2008). Co-Managing Wildlife in the Amazon and the Salvation of the Pacaya-Samiria National Reserve in Peru. In E. Duke (Ed.), Human Dimensions of Wildlife Management. Washington DC: Island Press.

Boyle, S. A., Lourenço, W. C., da Silva, L. R., \& Smith, A. T. (2009). Home Range Estimates vary with Sample Size and Methods. Folia Primatologica, 80, 33-42.

Burt, W. H. (1943). Territoriality and Home Range Concepts as Applied to Mammals. Journal of Mammalogy, 24(3), 346-352.

Cabrera, J. A. (2012). Natural licks and people: Towards an understanding of the ecological and social dimensions of licks in the Colombian Amazon. Canterbury: School of Antrhopology and Conservation, University of Kent.

Cagnacci, F., Boitani, L., Powell, R. A., \& Boyce, M. S. (2010). Animal ecology meets GPS-based radiotelemetry: a perfect storm of opportunities and challenges. Philosophical Transactions of the Royal Society B-Biological Sciences, 365, 2157-2162.

Calenge, C. (2006). The package "adehabitat" for the R software: A tool for the analysis of space and habitat use by animals. Ecological Modelling, 197, 516-519.

Castellanos, A. X. (2013). Iridium/GPS telemetry to study home range and population density of mountain tapirs in the rio Papallacta watershes, Ecuador. Tapir Conservation, 22(31), 20-25.

Fieberg, J., \& Kochanny, C. O. (2005). Quantifying home-range overlap: The importance of the utilization distribution. Journal of Wildife Management, 69(4), 1346-1359.

Fragoso, J. M. (2003). Long-distance seed dispersal by tapirs increases seed survival and aggregates tropical trees. Ecology, 84, 1998-2006.

Fragoso, J. M., \& Huffman, J. M. (2000). Seed-dispersal and seedling recruitment patterns by the last Neotropical megafaunal element in Amazonia, the tapir. Journal of Tropical Ecology, 16, 369-385.

Frair, J. L., Fieberg, J., Hebblewhite, M., Cagnacci, F., Decesare, N., \& Pedrotti, L. (2010). Resolving issues of imprecise and habitat-biased locations in ecological analyses using GPS telemetry data. Philosophical Transactions of the Royal Society B-Biological Sciences, 365, 2187-2200.

Hebblewhite, M., \& Haydon, D. T. (2010). Distinguishing technology from biology: a critical review of the use of GPS telemetry data in ecology. Philosophical Transactions of the Royal Society B-Biological Sciences, 36, 2303-2312.

International Union for Conservation of Nature Red List of Threatened Species. Version 2015.2. <www.iucnredlist.org>. Downloaded on 03 July 2015.

Keuroghlian, A., \& Eaton, D. P. (2009). Removal of palm fruits and ecosystem engineering in palm stands by white-lipped peccaries (Tayassu pecari) and other frugivores in an isolated Atlantic Forest fragment. Biodiversity and Conservation, 18, 1733-1750.

Kie, J. G., Matthiopoulos, J., Fieberg, J., Powell, R. A., Cagnacci, F., Mitchell, M. S., Gaillard, J. M., \& Moorcroft, P. R. (2010). The home-range concept: are traditional estimators still relevant with modern telemetry technology? Philosophical Transactions of the Royal Society B-Biological Sciences, 365, 2221-2231.

Kochanny, C. O., Delgiudice, G. D., \& Fieberg, J. (2009). Comparing Global Positioning System and very high frequency telemetry home ranges of white-tailed deer. Journal of Wildlife Management, 73(5), 779-787.

Lewis, J. S., Rachlow, J. L., Garton, E. O., \& Vierling, L. A. (2007). Effects of habitat on GPS collar performance: using data screening to reduce location error. Journal of Applied Ecology, 44, 663-671.

Mattisson, J., Andrén, H., Persson, J., \& Segerström, P. (2010). Effects of Species Behavior on Global Positioning System Collar Fix Rates. Journal of Wildlife Management, 743, 557-563.

Molina, E., León T. E., \& Armenteras-Pascual, D. (2014). Characteristics of natural salt licks located in the Colombian Amazon foothills. Environmental Geochemistry Health, 36(1), 117-129.

Murcia, U. G., Huertas, C. M., Rodríguez, J. M., \& Castellanos, H. O. A. (2010). Monitoreo de los bosques y otras coberturas de la Amazonia colombiana, datos del año 2007. Bogotá, D. C.: Instituto Amazónico de Investigaciones Científicas Sinchi.

Seaman, E. D., Millspaugh, J. J., Kernohan, B. J., Brundige, G. C., Raedeke, K. J., \& Gitzen, R. A. (1999). Effects of sample size on kernel home range estimates. Journal of Wildlife Management, 63(2), 739-747.

Schuttler, S. G., Blake, S., \& Eggert, L. S. (2012). Movement patters and spatial relationships among African forest elephants. Biotropica, 44(4), 445-448.

Telonics. (2013). GEN4 GPS Systems manual. 
Tobler, M. W. (2009). New GPS technology improves fix success for large mammal collars in dense tropical forest. Journal of Tropical Ecology, 25, 217-221.

Tobler, M. W., Carrillo-Percastegui, S. E., \& Powell, G. (2009). Habitat use, activity patterns and use of mineral licks by five species of ungulate in south-eastern Peru. Journal of Tropical Ecology, 25, 261-270.

Jung, T. S., \& Kuba, K. (2015). Performance of GPS collars on free-ranging bison (Bison bison) in north-western Canada. Wildlife Research, 42, 315.

Tomkiewicz, S. M., Fuller, M. R., Kie, J. G., \& Bates, K. K. (2010). Global positioning system and associated technologies in animal behaviour and ecological research. Philosophical Transactions of the Royal Society B-Biological Sciences, 365, 2163-2176.

UNEP-WCMC. (2012). CITES Trade: recent trends in international trade in Appendix II-listed species (1996-2010). Cambridge: UNEP-WCMC.

Walter, W. D., Fischer, J. W., Baruch-Mordo, S., \& Vercauteren, K. C. (2011). What Is the Proper Method to Delineate Home Range of an Animal Using Today's Advanced GPS Telemetry Systems: The Initial Step (Paper 1375). USDA National Wildlife Research Center - Staff Publications. 